\title{
Role of HPV 16 variants among cervical samples from Northeastern Brazil
}

Rodrigo Lopes da Silva

Universidade Federal do Maranhao

Zulmira da Silva Batista

Universidade Federal do Maranhao

Gerusinete Rodrigues Bastos

Universidade Federal do Maranhao

Ana Paula Almeida Cunha

Universidade Federal do Maranhao

Fábio Vidal Figueiredo

Universidade Federal do Maranhao

Lailson Oliveira de Castro

Universidade Federal do Maranhao

Liwerbeth dos Anjos Pereira

Universidade Federal do Maranhao

Marcos Antonio Custódio Neto da Silva

Universidade Estadual de Campinas

Flávia Castello Branco Vidal

Universidade Federal do Maranhao

Maria Claudene Barros

Universidade Estadual do Maranhao Centro de Estudios Superiores de Caxias

Elmary da Costa Fraga

Universidade Estadual do Maranhao Centro de Estudios Superiores de Caxias

Luciane Maria Oliveira Brito

Universidade Federal do Maranhao

Maria do Carmo Lacerda Barbosa

Universidade Federal do Maranhao

Miguel Ângelo Martins Moreira

Instituto Nacional de Cancer

Maria do Desterro Soares Brandão Nascimento ( $\nabla$ cnsd_ma@uol.com.br )

Universidade Federal do Maranhao https://orcid.org/0000-0003-2783-362X 
Keywords: Cervical cancer, Human papillomavirus, HPV 16, Variants

Posted Date: January 10th, 2020

DOI: https://doi.org/10.21203/rs.2.20515/v1

License: (c) (i) This work is licensed under a Creative Commons Attribution 4.0 International License. Read Full License 


\section{Role of HPV 16 variants among cervical samples from}

\section{Northeastern Brazil}

\section{Molecular variants of HPV 16 in Northeastern Brazil}

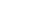

Rodrigo Lopes da Silva ${ }^{1 \pi}$, Zulmira da Silva Batista1币, Gerusinete Rodrigues

Bastos $^{1 \pi}$, Ana Paula Almeida Cunha ${ }^{1 \pi}$, Fábio Vidal Figueiredo¹, Lailson Oliveira de Castro ${ }^{2 \pi}$, Liwerbeth dos Anjos Pereira ${ }^{2 \pi}$, Marcos Antonio Custódio Neto da Silva ${ }^{3 \pi}$, Flávia Castello Branco Vidal ${ }^{1 \pi}$, Maria Claudene Barros ${ }^{4 \pi}$, Elmary da Costa Fraga $^{4 \pi}$, Luciane Maria Oliveira Brito ${ }^{1 \pi}$, Maria do Carmo Lacerda Barbosa $^{1 \pi}$, Miguel Ângelo Martins Moreira ${ }^{5 \pi}$, Maria do Desterro Soares Brandão Nascimento ${ }^{1 \pi *}$

${ }^{1}$ Post-graduate Program in Adult Health, Federal University of Maranhão (UFMA), São Luís, Maranhão, Brazil.

${ }^{2}$ Faculty of Medicine, Federal University of Maranhão (UFMA), São Luís, Maranhão, Brazil.

${ }^{3}$ Post-graduate Program in Internal Medicine, Faculty of Medical Sciences (FCM), State University of Campinas (UNICAMP), Campinas, São Paulo, Brazil.

${ }^{4}$ Center of Advanced Studies of Caxias (CESC), State University of Maranhão (UEMA), Caxias, Maranhão, Brazil. 
$1{ }^{5}$ Genetic Division, National Institute of Cancer (INCA), Rio de Janeiro, Rio de

2 Janeiro, Brazil.

* Corresponding author

$4 \quad$ E-mail: cnsd_ma@uol.com.br (MDSBN)

5 IT These authors contributed equally to this work.

\section{Abstract}

7 Background: Cervical cancer is the fourth most common type of cancer

8 affecting women globally. In Brazil, it is the third most frequent type of cancer in

9 women and HPV is present in approximately $90 \%$ of cases. Evidence suggests that variants of HPV 16 can interfere biologically and etiologically during the

11 development of cervical cancer. Methods: Cervix tumor fragments were

12 collected, their DNA was extracted, and nested PCR was used to detect HPV.

13 Positive samples were sequenced to determine the viral genotype. To characterize the HPV 16 strains, positive samples PCR was used to amplify the LCR and E6 regions of the HPV 16 virus. Results: Data from 120 patients with cervical cancer were analyzed. Most women were between 41 and 54 years of age, had schooling until primary school, a family income between 1 and 2 times the minimum wage and were married/in a consensual union. There was no statistically significant association between HPV or socio-demographic variables and risk factors for cervical cancer $(P<0.05)$. HPV was present in 88 women (73\%). The most prevalent types were HPV 16 (47/54\%), HPV 18 (12/13.8\%), HPV 35 (6/6.9\%) and HPV 45 (5/5.7\%). Of the 47 HPV 16 positive cases, variant A (49\%) was present in 23 samples, followed by variant D in 20 cases (43\%), and variants B and C in 2 cases each (4\%). The most prevalent 
1 histological type of HPV 16 tumors was epidermoid carcinoma, followed by

2 adenocarcinoma. There was a statistically significant association between HPV

316 variants and the tumors' histological types $(P<0.001)$. Conclusions:

4 Knowledge of HPV 16 variants will provide data on their influence on the

5 pathological and oncogenic aspects of cervical lesions.

6 Keywords: Cervical cancer; Human papillomavirus; HPV 16; Variants.

\section{Background}

8

Cervical cancer is the fourth most common cancer type affecting women worldwide, with more than 265,000 estimated deaths annually and more than $80 \%$ of cases occurring in developing countries [1,2]. According to INCA, cervical cancer is the third most common cancer type in the Brazilian female population. They estimate that there will be 16,370 new cervical cancer cases for the biennium from 2018-2019 [3].

It is estimated that in the state of Maranhão there will be around 1,090 new cervical cancer cases for 2018, with240 of them the capital, São Luís, with a gross rate of incidence of 30.55 cases per 100,000 inhabitants [3].

Human Papillomavirus (HPV) is the main etiological factor for cervical cancer and is associated with the development of diseases ranging from benign warts to invasive cancer [4]. Although approximately $80 \%$ of women acquire HPV infection by the age of 50 , less than $1 \%$ of persistent infections progress to invasive cervical cancer [5]. 
1

2

The reason why only some uterine cervical lesions associated with highrisk genotypes progress to invasive cancer remains unknown. Evidence suggests that variants of the same HPV type can interact biologically and etiologically during cancer development $[6,7]$.

The HPV16 is the most carcinogenic HPV type followed by HPV18 and most infections are asymptomatic [8]. A few studies have been conducted in Brazil on HPV 16 variants. This type of study has never been conducted in Maranhão. Interest in this topic has been growing in recent years, with variation in carcinoma prognosis at different stages of the disease depending on the viral variant found attracting special interest. Even in research carried out other places in the world, many of these questions remain unclear and many of the findings are contradictory, making it necessary to develop new and continuous approaches to this topic.

Despite of the relationship between different HPV type and the development of cancer being well established, evidence suggests that genetic variations between the same viral type may influence infection potential, viral persistence, the development of precursor lesions and the progression to invasive cancer [9-12]. Due to the high prevalence of HPV 16 in cases of cervical cancer, the association between HPV 16 and cancer has been studied at the level of intratype variants, and several lines of study have attributed a higher risk of invasive cervical cancer to some HPV 16 strains.

Studies on HPV variants have been developed with the objective of understanding their association with pathological and oncogenic aspects of cervical lesions. Factors influencing HPV infection in cervical cancer are not completely clear, but it is believed that HPV 16 variants playa fundamental role 
1 in cervical carcinogenesis and are currently recognized as an important marker

2 for research on viral transmission, persistence and carcinogenicity [5]. Variation

3 in these aspects may contribute to disparities in cervical cancer incidence.

\section{Methods}

5

6 Type of Study

7

This is descriptive, prospective, and transversal study.

\section{Period and Location of study}

The study was conducted from January 2016 to December 2017, at the High Complexity Care Unit (UNACON) of the Cancer State Hospital of Maranhão and in the High Complexity Care Center in Oncology (CACON) of the Aldenora Bello Cancer Hospital.

\section{Population and Sample}

The study population was composed of 120 women with a diagnosis of cervical cancer, who were treated at the previously mentioned hospitals.

\section{Inclusion criteria}

Women older than 18 years diagnosed with cervical cancer who agreed to participate in the study by signing an Informed Consent Form (ICF).

\section{Exclusion criteria}

Women who presented with surgical indications as an initial treatment or who presented with small lesions, in which biopsy could interfere with staging. Women in psychiatric treatment were also excluded. 


\section{Sample Calculation}

2

According to estimates by the National Cancer Institute (INCA), the

3 number of cases of cervical cancer malignant neoplasms in São Luis is 230

4 new cases for 2016. Since is a finite sample of less than 100,000 individuals we used the following formula:

6

7

8

9

10

11

12

13

14

13 with $n_{o}$ equalto:

$$
\mathrm{n}=\frac{\mathrm{n}_{0}}{1+\frac{\mathrm{n}_{0}-1}{\mathrm{~N}}}
$$

Legend:

$\boldsymbol{n}_{0}=$ sampling intensity;

N = Population Sample Size$$
n_{0}=\frac{z(k)^{2}}{4 d^{2}}
$$

Legend:

$\mathrm{z}(\mathrm{k})^{2}=$ value in the Student's t-test table with $(\mathrm{n}$ -

1) degrees of freedom for the confidence interval;

$d=$ error 
1

2 São Luís population by INCA, with a confidence interval of $95 \%$ and sample error of $5 \%$ we have the following values:

$$
n_{0}=\frac{1.96^{2}}{4(0.05)^{2}}=384.16
$$

5

Substituting $n_{0}$ into the equation, we have:

7

$$
n=\frac{384.16}{1+\frac{(384.16-1)}{230}}=144.15
$$

9

Thus, based on our population, 144 samples are indicated.

\section{Collection instrument and data evaluation}

Initially, the patients were referred for outpatient care at the Oncology

Gynecology Service of the Cancer State Hospital of Maranhão and the Aldenora

Bello Cancer Hospital and were invited to participate in the study by signing an Informed Consent Form (ICF). A questionnaire was supplied to collect sociodemographic, reproduction, and smoking data.

Cervical tumor fragments identified by gynecological examination were then placed in microtubes containing $1 \mathrm{~mL}$ of RNA Later solution (Life Technologies) at $4^{\circ} \mathrm{C}$ and were transported in thermal boxes to the Multiuser Laboratory in the Biobank of Tumors and DNA of Maranhão of the Federal University of Maranhão, University Hospital of the Federal University of 
1 Maranhão-HUUFMA. After 24 hours, the samples were removed from the RNA

2 Later solution and stored in a freezer at $-80^{\circ} \mathrm{C}$ until use.

\section{Experimental Procedures}

\section{DNA Extraction}

5

6

7

DNA was extract with a Dneasy Blood \&Tissue Kit (QIAGEN Ltd., UK) according to the manufacturer's directions. Briefly, up to $25 \mathrm{mg}$ of tumor tissue was sectioned with a sterile razor and deposited in $2 \mathrm{~mL}$ tubes, where they were resuspended in $180 \mu \mathrm{L}$ of lysis buffer (ATL) and $20 \mu \mathrm{L}$ of Proteinase $\mathrm{K}$. The tubes were incubated at $56{ }^{\circ} \mathrm{C}$ in a thermomixer for $24 \mathrm{~h}$ for tissue lysis.

$200 \mu \mathrm{L}$ of $\mathrm{AL}$ Buffer was then added to the mixture which was homogenized in a vortex for $15 \mathrm{~s}$. The tubes were then incubated at $90^{\circ} \mathrm{C}$ for 1 hour in a thermomixer, $200 \mu \mathrm{L}$ of ethanol P.A. (Merck, BR) was added to the sample and it was again homogenized in the vortex.

The mixture was transferred to a tube containing a silica column (QIAamp MinElute) and centrifuged at 8,000 rpm for 2 minutes. After centrifugation, the column was repositioned in a new collector tube, and the filtrate was discarded.

The column was then washed successively with $500 \mu \mathrm{L}$ of wash buffer 1 and wash buffer 2 centrifuging at $8,000 \mathrm{rpm}$ for 2 minutes between washes. The column was then incubated with $100 \mu \mathrm{L}$ of $\mathrm{AE}$ Buffer at room temperature for 5 minutes before being centrifuged at $14,000 \mathrm{rpm}$ for 4 minutes to obtain the DNA. The samples were identified and stored at $-20^{\circ} \mathrm{C}$ for later use in PCR reactions. 


\section{DNA Quantification}

The extracted DNA was quantified by reading absorbance in a Nanovue spectrophotometer (GE) at a wave length of $260 \mathrm{~nm}$. The purity of the DNA was verified by reading at $280 \mathrm{~nm}$ to detect possible protein contamination. The samples were considered pure when the A260/A280 ratio was between 1.6 and 1.9 .

\section{Detection of HPV DNA by Nested PCR}

HPV DNA in the cervical tumor samples was identified by Nested PCR using a Veriti 96 Well Thermal Cycler (Applied Biosystems, Thermo Scientific, California, USA). This technique consists of amplifying the DNA of interest in two rounds and using specific primers for round. With two rounds of PCR, the first amplification is more general and the second reaction, which uses the Amplicon produced in the first round as a template, leads to amplification of smaller and more specific sequences of viral DNA.

In the first-round, the primers PGMY 09 and 11 (Table 1) were used to amplify 450 bp sequences of the L1 region of viral DNA; in the second round, the primers GP +5 and GP +6 were used to amplify $190 \mathrm{bp}$ sequences of the L1 region of the viral DNA [12]. We used samples known to be positive as a positive control and water as a negative control.

To minimize the possibility of external contamination, the reactions were prepared in a laminar flow chapel exposed to ultraviolet light for approximately 15 minutes, along with all plastic material used. 
1 Table 1. Primer sequences used for the Nested PCR reaction to identify HPV

2 DNA.

\begin{tabular}{|c|c|c|}
\hline Primer & Sequence $5^{\prime}$ - & \\
\hline \multirow[t]{5}{*}{ PGMY11 } & PGMY11-A & GCA CAG GGA CAT AAC AAT GG \\
\hline & PGMY11-B & GCG CAG GGC CAT AAT AAT GG \\
\hline & PGMY11-C & GCA CAG GGA CAT AAT AAT GG \\
\hline & PGMY11-D & GCC CAG GGC CAC AAC AAT GG \\
\hline & PGMY11-E & GCT CAG GGT TTA AAC AAT GG \\
\hline \multirow[t]{13}{*}{ PGMY09 } & PGMY09-F & CGT CCC AAA GGA AAC TGA TC \\
\hline & PGMY09-G & CGA CCT AAA GGA AAC TGA TC \\
\hline & PGMY09-H & CGT CCA AAA GGA AAC TGA TC \\
\hline & PGMY09-la & G CCA AGG GGA AAC TGA TC \\
\hline & PGMY09-J & CGT CCC AAA GGA TAC TGA TC \\
\hline & PGMY09-K & CGT CCA AGG GGA TAC TGA TC \\
\hline & PGMY09-L & CGA CCT AAA GGG AAT TGA TC \\
\hline & PGMY09-M & CGA CCT AGT GGA AAT TGA TC \\
\hline & PGMY09-N & CGA CCA AGG GGA TAT TGA TC \\
\hline & PGMY09-Pa & G CCC AAC GGA AAC TGA TC \\
\hline & PGMY09-Q & CGA CCC AAG GGA AAC TGG TC \\
\hline & PGMY09-R & CGT CCT AAA GGA AAC TGG TC \\
\hline & HMB01b & GCG ACC CAA TGC AAA TTG GT \\
\hline \multirow[t]{2}{*}{$\mathrm{GP}+5 / 6$} & $\mathrm{GP}+5$ & TTT GTT ACT GTG GTA GAT ACT AC \\
\hline & $\mathrm{GP}+6$ & GAA AAA TAA ACT GTA AAT CAT ATT C \\
\hline
\end{tabular}


The reaction conditions using primers PGMY09/11 were initial denaturation for 2 minutes at $95^{\circ} \mathrm{C}$ followed by 40 cycles of denaturation for 40 seconds at $95^{\circ} \mathrm{C}$, annealing for 40 seconds at $55^{\circ} \mathrm{C}$, and extension for 40 seconds at $72^{\circ} \mathrm{C}$. The reaction mixture consisted of a final volume of $25 \mu \mathrm{L}$ containing $10 \mathrm{pmol}$ of each primer, $2.5 \mu \mathrm{L}$ of $10 \mathrm{x}$ reaction buffer, $0.5 \mu \mathrm{L}$ of magnesium chloride at $50 \mathrm{Mm}, 10 \mathrm{Mm}$ of dNTP and $0.2 \mu \mathrm{L}$ of Taq polymerase Platinum (Invitrogen) [15].

The reaction conditions for the second round of the Nested PCR with primers GP5 +/GP6+ was an initial denaturation of 4 minutes at $95^{\circ} \mathrm{C}$ followed by 45 cycles of denaturation for 45 seconds at $95^{\circ} \mathrm{C}$ for 1 min, annealing for 1 minute at $40{ }^{\circ} \mathrm{C}$ and extension for 1 minute at $72^{\circ} \mathrm{C}$. The reaction mixture consisted of a final volume of $25 \mu \mathrm{L}$, containing $10 \mathrm{pmol}$ of each primer, $2.5 \mu \mathrm{L}$ of $10 \mathrm{x}$ buffer, $1.5 \mu \mathrm{L}$ of magnesium chloride at $50 \mathrm{Mm}, 10 \mathrm{Mm}$ of dNTP and 0.3 $\mu \mathrm{L}$ of Taq polymerase Platinum (Invitrogen) [15].

\section{Visualization of amplified products}

$5 \mu \mathrm{L}$ aliquots of each reaction with loading buffer (Sigma-Aldrich, USA) and $0.1 \%$ Gel Red dye were visualized by electrophoresis in $1.5 \%$ agarose gel in TBE 1X buffer.

\section{Purification of PCR products}

The PCR products were purified with a Genelute PCR Clean up Kit according to the manufacturer's protocol (Sigma-Aldrich, USA). Briefly, $500 \mu \mathrm{L}$ of capture buffer was added to $100 \mu \mathrm{L}$ of PCR product in each microtube. The material was centrifuged and $2 \mu \mathrm{L}$ of purified DNA was run in a $2 \%$ agarose gel to evaluate the purified sample. 


\section{Automatic sequencing}

HPV genotypes were determined by automated sequencing of the PCR products using a1000 MegaBACE sequencer (GE Healthcare, UK)at the Molecular Biology Laboratory of the State University of Maranhão located in the Center of Higher Studies of Caxias (CESC-UEMA).

Sequencing was performed with an ET Dye Terminator Cycle Sequencing Kit (GE Healthcare, UK), according to the manufacturer's protocol. Each reaction contained $2 \mu \mathrm{L}$ of the purified PCR product, $40 \mathrm{ng}$ of specific oligonucleotides for the specific exon (sense or antisense) and $2 \mu \mathrm{L}$ of the Big Dye kit.

The Chromas program was used to obtain electropherograms of the HPV DNA sequences present in the samples. To identify the HPV type the nucleotide sequences were compared to the Genbank Nucleotide Sequence Database using the BLAST program (NCBI).

\section{Identification of HPV 16 variants}

After determination of the HPV 16 strains, the LCR regions and E6 virus gene of the positive samples were amplified with specific primers. The reaction mixture consisted of a final volume of $25 \mu \mathrm{L}$, with 1 X PCR Buffer, $2.5 \mathrm{mM}$ of $\mathrm{MgCl}_{2}, 0.25 \mu \mathrm{M}$ of each dNTP, $100 \mathrm{pmol} / \mathrm{L}$ of each primer, $50-100 \mathrm{ng}$ of DNA, and 2.5 U of Platinum Taq Polymerase. The PCR reaction consisted of denaturation at $95^{\circ} \mathrm{C}$ for $10 \mathrm{~min}$, followed by 40 cycles of $95^{\circ} \mathrm{C}$ for $1 \mathrm{~min}$; annealing temperature for $1 \mathrm{~min}$ and $72{ }^{\circ} \mathrm{C}$ for $1 \mathrm{~min}$, followed by a final extension step for $15 \mathrm{~min}$. 
1 The PCR product was subsequently purified and sequenced according to

2 the above protocol. The consensus sequences were merged using the

3 Geneious software (Biomatters Ltd.) and all the sequences generated were

4 aligned with HPV 16 specific strains, using the reference sequences proposed

5 by Burk et al (2013), using the MEGA Software (version 6.0,

6 www.megasoftware.net). BLAST online (Available at:

7 http://www.ncbi.nlm.nih.gov/blast/Blast.cgi) was then used to identify the HPV 8 types.

\section{$9 \quad$ Statistical analyses}

Descriptive statistical analysis was performed using the Stata program

11 (version 14.0). The $x^{2}$ (Chi-square) test was used to verify the association between HPV and sociodemographic and clinical variables, and $\mathrm{P}$ values $\leq 0.05$ were considered statistically significant. The values corresponding to don't know/did not respond were excluded from the association analysis.

\section{Phylogenic Analysis}

The phylogenetic tree of the HPV 16 strains was constructed from the

1,300bp sequences from the E6 and LCR regions using the "neighbor joining" method with p-distance (obtained with pairwise deletion) using the program Mega 4.1. The references proposed by Burk et al. (2013) [20] were included. The analysis of the HPV 16 variants was performed at the National Cancer Institute (INCA) under the supervision of Dr. Miguel Ângelo Martins Moreira. 


\section{RESULTS}

\section{Sociodemographic and clinical data}

3

4 in $88(73.3 \%)$. The majority of these women were in the age group 40 to 49

5 years of age (34/28.33\%), and self-declared with mixed-race (84/70\%), had

6 schooling up to elementary school (51/42.50\%), had a family income

7 between 1 and 2 times the minimum wage (66/55\%) and were married or in a 8 consensual union (62/51.67\%). There was no statistically significant 9 association between the sociodemographic variables and the presence of $10 \operatorname{HPV}(p<0.05)($ Table 2$)$.

Table 2. Association between sociodemographic factors and the presence of Human Papillomavirus.

\section{HPV}

\begin{tabular}{lllllllll} 
Sociodemographic Variables & \multicolumn{1}{l}{ Total } & Negative & Positive & \\
\cline { 2 - 5 } & & & & & & & & p-value
\end{tabular}

\begin{tabular}{|c|c|c|c|c|c|c|c|}
\hline Age (Years) & & & & & & & \\
\hline$\leq 29$ & 8 & (6.67) & 4 & 50.00 & 4 & 50.00 & \multirow{6}{*}{0.421} \\
\hline 30 to 39 & 20 & (16.67) & 5 & 25.00 & 15 & 75.00 & \\
\hline 40 to 49 & 34 & (28.33) & 9 & 26.47 & 25 & 73.53 & \\
\hline 50 to 59 & 19 & (15.83) & 7 & 36.84 & 12 & 63.16 & \\
\hline 60 to 69 & 19 & (15.83) & 4 & 21.05 & 15 & 78.95 & \\
\hline$\geq 70$ & 20 & (16.67) & 3 & 15.00 & 17 & 85.00 & \\
\hline
\end{tabular}




$\begin{array}{lccccccc}\text { Ethnicity } & 20 & (16.67) & 3 & 15.00 & 17 & 85.00 & \\ \text { European-descent } & 13 & (10.83) & 2 & 15.38 & 11 & 84.62 & \\ \text { African-descent } & 3 & (2.5) & 1 & 33.33 & 2 & 66.67 & 0.377 \\ \text { East Asian- descent } & 84 & (70) & 26 & 30.95 & 58 & 69.05 & \\ \text { Mixed-race } & & & & & & & \\ \text { Marital Status } & 39 & (32.5) & 12 & 30.77 & 27 & 69.23 \\ \text { Single } & 62 & (51.67) & 14 & 22.58 & 48 & 77.42 & \\ \text { Married/Consensual Union } & 6 & (5) & 2 & 33.33 & 4 & 66.67 & 0.774 \\ \text { Divorced/Separated } & 13 & (10.83) & 4 & 30.77 & 9 & 69.23\end{array}$

\section{Family Income}

$\begin{array}{lllllll}\text { Less than the minimum wage } & 29 & (24.17) & 7 & 24.14 & 22 & 75.86\end{array}$

$\begin{array}{lllllll}1 \text { to } 2 \text { times the minimum wage } & 66 & \text { (55) } & 18 & 27.27 & 48 & 72.73\end{array}$

$\begin{array}{lllllll}\text { Above } 2 \text { times the minimum wage } \quad 20 & (16.67) & 4 & 20.00 & 16 & 80.00\end{array}$

0.797

Don't Know/Didn't Answer

$\begin{array}{llllll}5 & (4.16) & 3 & 60.00 & 2 & 40.00\end{array}$

$\begin{array}{lcccccc}\text { Education } & 41 & (34.17) & 13 & 31.74 & 28 & 68.29 \\ \text { None } & 4 & (3.33) & 0 & 0.00 & 4 & 100.0 \\ \text { Adult Education } & & & & & & \\ \text { Primary Education/Primary Level } & 51 & (42.50) & 11 & 21.57 & 40 & 78.43 \\ \text { High School/Secondary Level } & 20 & (16.67) & 8 & 40.00 & 12 & 60.00 \\ \text { Higher Incomplete } & 1 & (0.83) & 0 & 0.00 & 1 & 100.0 \\ \text { Higher Complete } & 1 & (0.83) & 0 & 0.00 & 1 & 100.0\end{array}$


1 8 (Table 3).

9

Of the risk factors associated with cervical cancer, for most women first sexual intercourse occurred between 10 and 19 years of age (87/72.50\%), a first pregnancy between 16 and $21(41 / 34.17 \%)$ and 1 to 3 children (37/30.83\%) were most common. Having only one sexual partner during their lifetime $(38 / 31.67 \%)$ was most common followed by more than 3 partners $(36 / 30 \%)$. Most women reported never having used contraceptive methods (70/58.33\%)

Table 3. Association between cervical cancer risk factors, reproductive history and presence of HPV

\section{HPV}

Risk Factors

Total

Negative

Positive

p-value

\begin{tabular}{llllll}
\hline $\mathrm{n}$ & $\%$ & $\mathrm{~N}$ & $\%$ & $\mathrm{~N}$ & $\%$
\end{tabular}

\begin{tabular}{|c|c|c|c|c|c|c|c|}
\hline \multicolumn{8}{|c|}{ Onset of sexual activity (years) } \\
\hline 10 to 19 & 87 & $(72.50)$ & 25 & 28.74 & 62 & 71.26 & \multirow{4}{*}{0.738} \\
\hline 20 to 29 & 9 & $(7.50)$ & 3 & 33.33 & 6 & 66.67 & \\
\hline Above 30 & 2 & $(1.67)$ & 0 & 0.00 & 2 & 100.0 & \\
\hline $\begin{array}{l}\text { Don't Know/ Did not } \\
\text { answer }\end{array}$ & 22 & $(18.33)$ & 4 & 18.18 & 18 & 81.82 & \\
\hline \multicolumn{8}{|l|}{ Age at $1^{\text {st }}$ pregnancy } \\
\hline 11 to 15 & 11 & $(9.17)$ & 1 & 9.09 & 10 & 90.01 & \multirow[t]{2}{*}{0.268} \\
\hline 16 to 21 & 41 & $(34.17)$ & 14 & 34.15 & 27 & 65.85 & \\
\hline
\end{tabular}




\begin{tabular}{|c|c|c|c|c|c|c|c|}
\hline 22 to 27 & 13 & $(10.83)$ & 5 & 38.46 & 8 & 61.54 & \\
\hline Above 27 & 2 & $(1.67)$ & 0 & 0.00 & 2 & 100.0 & \\
\hline $\begin{array}{l}\text { Don't Know/ Did not } \\
\text { answer }\end{array}$ & 53 & $(44.17)$ & 12 & 22.41 & 41 & 77.36 & \\
\hline \multicolumn{8}{|l|}{ Number of pregnancies } \\
\hline 1 to 3 & 37 & $(30.83)$ & 11 & 29.73 & 26 & 70.27 & \multirow{6}{*}{0.859} \\
\hline 4 to 6 & 26 & $(21.67)$ & 6 & 23.08 & 20 & 76.92 & \\
\hline 7 to 9 & 32 & $(26.67)$ & 8 & 25.00 & 24 & 75.00 & \\
\hline 10 to 12 & 13 & $(10.83)$ & 4 & 30.77 & 9 & 69.23 & \\
\hline Above 12 & 8 & $(6.67)$ & 1 & 12.50 & 7 & 87.50 & \\
\hline Don't Know / Did not answer & 4 & $(3.33)$ & 2 & 50.0 & 2 & 50 & \\
\hline \multicolumn{8}{|l|}{ Use of contraceptive } \\
\hline Yes. Actually Use & 7 & $(5.83)$ & 2 & 28.57 & 5 & 71.43 & \multirow{4}{*}{0.887} \\
\hline Yes. Already Used & 40 & (33.33) & 12 & 30.00 & 28 & 70.00 & \\
\hline No & 70 & $(58.33)$ & 18 & 25.71 & 52 & 74.29 & \\
\hline $\begin{array}{l}\text { Don't Know /Did not } \\
\text { answer }\end{array}$ & 3 & $(2.50)$ & 0 & 0.00 & 3 & 100 & \\
\hline \multicolumn{8}{|l|}{ Number of sexual partners } \\
\hline 1 & 38 & $(31.67)$ & 11 & 28.95 & 27 & 71.05 & \multirow{4}{*}{0.406} \\
\hline 2 & 27 & $(22.50)$ & 4 & 14.81 & 23 & 85.19 & \\
\hline$\geq 3$ & 36 & $(30.00)$ & 8 & 22.22 & 28 & 77.78 & \\
\hline Don't know/Did not answer & 19 & $(15.83)$ & 9 & 47.37 & 10 & 52.63 & \\
\hline
\end{tabular}

1

2 Most women (84/70\%) reported having undergone examination before

3 their diagnosis with cervical cancer and most (44/36.67\%) said they received 
1 preventive exam annually. Most women reported no tobacco use (69

$2 \quad 157.50 \%)($ Table 4$)$.

\begin{tabular}{|c|c|c|c|c|c|c|c|}
\hline \multirow{3}{*}{ Risk Factors } & \multicolumn{7}{|c|}{ HPV } \\
\hline & \multicolumn{2}{|c|}{ Total } & \multicolumn{2}{|c|}{ Negative } & \multicolumn{2}{|c|}{ Positive } & \multirow[t]{2}{*}{ p-value } \\
\hline & $\mathrm{n}$ & $\%$ & $\mathrm{n}$ & $\%$ & $\mathrm{n}$ & $\%$ & \\
\hline \multicolumn{8}{|c|}{ Preventive examination before diagnosis } \\
\hline No & 29 & $(24.17)$ & 12 & 41.38 & 17 & 58.62 & \\
\hline Yes & 84 & $(70.00)$ & 20 & 23.81 & 64 & 76.19 & 0.070 \\
\hline $\begin{array}{l}\text { Don't Know/ Did not } \\
\text { Answer }\end{array}$ & 7 & $(5.83)$ & 0 & 0.00 & 7 & 100.00 & \\
\hline \multicolumn{8}{|l|}{ Frequency of Pap test } \\
\hline Every Year & 44 & $(36.67)$ & 12 & 27.27 & 32 & 72.73 & \multirow{7}{*}{0.153} \\
\hline Every 2 Years & 9 & $(7.50)$ & 1 & 11.11 & 8 & 88.89 & \\
\hline Every 3 Years & 1 & $(0.83)$ & 1 & 100.0 & 0 & 0.00 & \\
\hline & & & & & & & \\
\hline 4 years or more & 1 & $(0.83)$ & 1 & 100.0 & 0 & 0.00 & \\
\hline Without Regularity & 32 & $(26.67)$ & 8 & 25.00 & 24 & 75.00 & \\
\hline Don't Know/ Did not answer & 33 & $(27.50)$ & 9 & 27.27 & 24 & 72.73 & \\
\hline \multicolumn{8}{|l|}{ Smoking } \\
\hline No & 69 & $(57.50)$ & 22 & 31.88 & 47 & 68.12 & \multirow{3}{*}{0.208} \\
\hline & & & & & & & \\
\hline Yes & 43 & $(35.83)$ & 9 & 20.93 & 34 & 79.07 & \\
\hline
\end{tabular}
presence of Human Papillomavirus

\section{HPV}

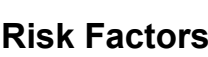

Preventive examination before diagnosis

Table 4. Association between preventive examination, smoking and the

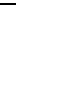

\section{(1)}


$\begin{array}{lllllll}\text { Don'tKnow/ Did not answer } & 8 & (6.67) & 1 & 12.50 & 7 & 87.50\end{array}$

1

\section{Identification of HPV type}

3

4 type among the analyzed cases and combined with HPV 18 accounted for

6

7

8

HPV was present in 88 women (73.33\%). HPV 16 was the most prevalent $68.17 \%$ of cases. Most of the samples had HPV types considered high risk, while less than $3.4 \%$ had HPV types considered to have low oncogenic risk (Fig 1).

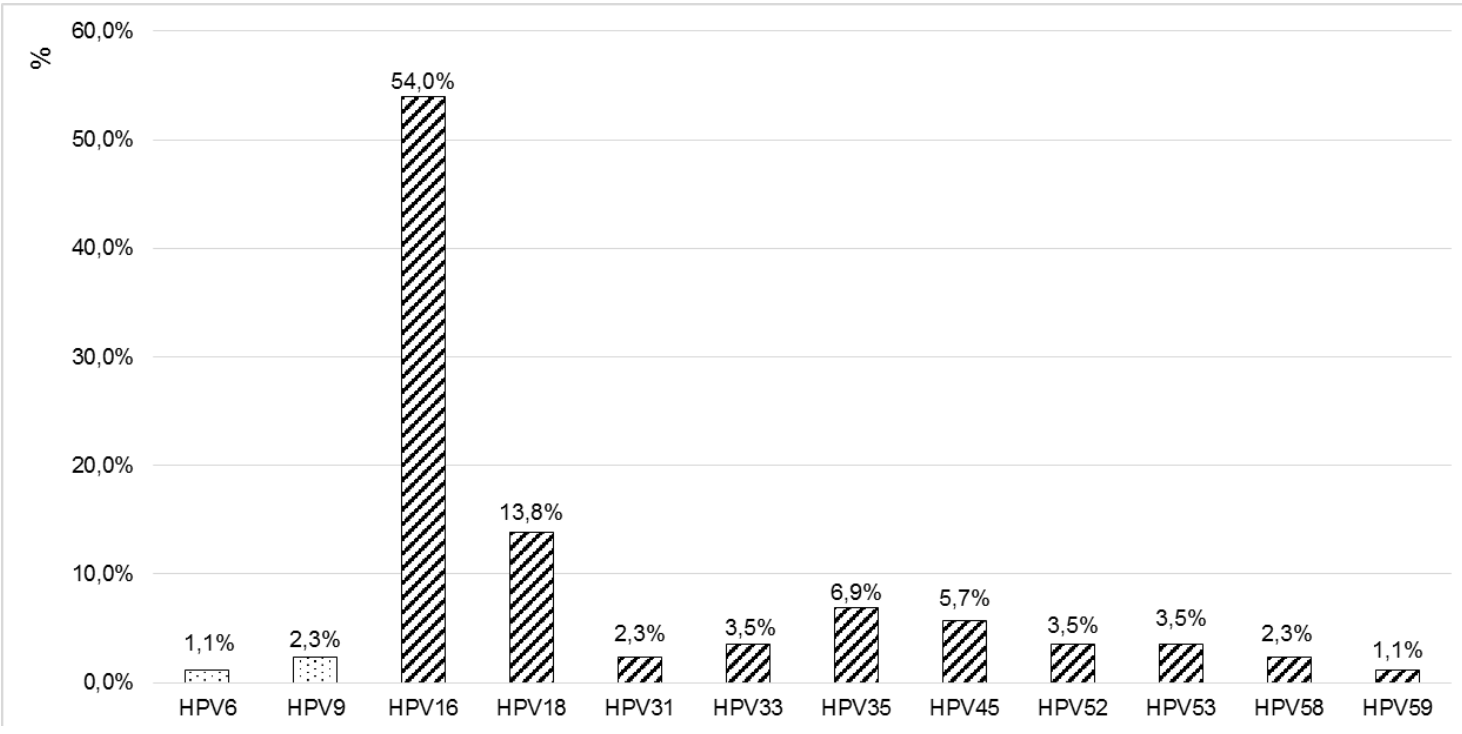

\section{Histological types of analyzed tumors}

The most prevalent types of tumor histological types were epidermoid carcinoma (EC) with a total of 95 cases $(79.1 \%)$ and $11(9.1 \%)$ cases of adenocarcinomas. Of the 120 women in this study, 45 (37.5\%) had stage IIIB tumors, in cases where HPV 16 was present, stage III was predominant with 23 samples. 
1

2 3

4

5

6

7

8

9

\section{HPV 16 Variants}

Of the 47 samples identified as HPV 16, 23 samples were variant $A$ (49\%), $20(43 \%)$ were variant D, while variants B and C were present in two samples each (4\%).

The mean age for women with variant A of HPV 16 was 50.6 years, 58.5 years for variant $B, 58.5$ years for variant $C$ and 50 years for those with variant

D. The most prevalent histological type in tumors with HPV 16 was squamous cell carcinoma (SCC) in 38 samples, followed by adenocarcinoma in 4 samples $(11 \%)$

There was a statistically significant association between histological type and HPV variant $(p<0,001)$, regarding squamous cell carcinoma and HPV 16 variant "A" and "D". Staging also changed depending on the HPV 16 variant. Among patients with variant $A$, stage III (9 patients) was predominant followed by stage II (8 cases). For those with variant D, clinical stage III (10 cases) was predominant, followed by stage II (4 cases).

Treatment response also depended on the HPV 16 variant. For example, 12 cases with variant $A$ showed complete remission, compared to only 7 cases with variant $D$. Likewise, there were 2 deaths with variant $A$, and 3 who had variant D. In 12 cases it was not possible to evaluate disease status at the end of the first treatment.

A reference sequence described by Burk et al. (2013) was used to construct the phylogenetic tree. Among HPV 16 cervical samples classified as belonging to variant $A, 21$ belonged to sublineage $A 1,1$ belonged to sublineage 
$1 \mathrm{~A} 2$ and 1 belonged to sublineage $\mathrm{A} 4$. Of the samples belonging to variant $\mathrm{B}, 1$

2 belonged to sublineage $B 1$ and 1 belonged to sublineage $B 2$.

3

Of the HPV 16 cervical samples belonging to variant $D, 1$ belonged to

4 sublineage D1, 1 belonged to sublineage D2 and 18 belonged to sublineage

5 D3. Variant C, with 2 cases, does not have any sublineages (Fig 2). 


\section{Discussion}

2 Cervical cancer is associated with low socioeconomic indices, presenting

3 a higher prevalence in regions with high poverty, high illiteracy rates and

4 precarious hygiene habits $[13,14]$.

5 The virus was highly prevalent $(88 / 120-73 \%)$ in the tumor samples

6 examined. The prevalence of HPV in invasive cervical cancer samples can

7 range from $70 \%$ to $100 \%$, which may be associated with different techniques

8 used to detect the virus [15-17].

HPV 16 is the most prevalent in cervical cancer worldwide, followed by HPV 18. However, the frequency of HPV types may vary according to the geographic region of the population under analysis. Other studies point out that types16, 18, 31, and 45as the four most prevalent HPV types in South and Central America $[18,19]$.

Studies have sought to evaluate the role of intratype variants of HPV16 and HPV18 in the persistence of viral infection, the risk of cervical intraepithelial neoplasia development, and the development of invasive cervical cancer $[11,20]$.

For both HPV 16 and HPV 18, the distribution of variants worldwide is influenced by geographic and ethnic factors.

In a case-control study conducted by Hang et al. (2016) [5], we attempted to evaluate the association between HPV 16 variants and the risk of cervical cancer in 298 women with HPV 16 in China and found that variant A was predominant. 
In the study conducted by Volpini et al., (2017) [21] in Brazil on 24

2 women positive for HPV 16, with and HIV diagnosis, but anormal Pap smear,

3 variant $A$ accounted for $70.8 \%$ of cases $(17 / 24)$, followed by the $C$ and $D$

4 variants, which together totaled $29.2 \%$ of the samples (7/24). Variant B was not

5 found in that study.

$6 \quad$ In a study conducted in Brazil by Vidal et al. (2016) [12] on a cohort of

7594 women with invasive cervical cancer, 334 women had HPV 16. Of these,

$8217(65 \%)$ belonged to variant A, $97(29 \%)$ belonged to variant D. Variants B 9 and $\mathrm{C}$ had 10 cases (3\%) each.

A study by Villa et al. (2000) [22], also in Brazil, examined the geographic differences in intratype variations of HPV 16 and their associations with the development of cervical cancer precursor lesions. Variant A (54\%) was the most frequent, followed by variant $D$ in $22 \%$ of the cases. It also emphasizes the strong association between persistence and the presence of the nonin the population studied was variant A for HPV 16, followed by variant D. In the study by Hang et al. (2016) [5], it was observed among the cases of women with cervical cancer infected with HPV 16, 289 (97\%) had a pattern of 
1 squamous cell carcinoma, followed by adenocarcinoma (2.3\%) and 2 adenosquamous carcinoma $(0.7 \%)$.

Few studies have been conducted to evaluate the effect of HPV 16 variants on the response to oncologic treatment. After analyzing 155 cases of HPV16 positive cervical cancer (132 cases of variants $E \times 23$ cases of NE variants) Zuna et al (2011) [25] came to the conclusion that the non-European variants showed less aggressive behavior in relation to mortality than the European variants. It should be pointed out that the data should be evaluated with caution due to the small number of cases of NE variants in the study.

In our study we found a greater number of $N E$ variants $(B, C$, and $D)$. Of the 47 cases we found 23 with variant $A(E)$ and 24 with variants $B, C$, and $D$. The mortality of patients with the NE variants was $13 \%(3 / 24)$, while it was $9 \%$ $(2 / 23)$ in those with variant $A(E)$. The number of cases of complete remission was also lower with the NE variants $(33 \% \times 52 \%)$. These findings can be explained by the large number of cases of variant $D$ in our study (20 cases). $A$ study by Burk et al (2013) [20], showed the specific aggressiveness of this variant.

We observed the predominance of sublineage A1 (21 cases), followed by sublineage D3 (18 cases). In the study by Hang et al (2016) [5], the A4 sublineage was associated with a significantly higher risk of cervical cancer than the $\mathrm{A} 1-\mathrm{A} 3$ sublineages $(\mathrm{OR}=1.72,95 \% \mathrm{Cl})$.

In a study by Alfaro et al., (2016) [26] of 462 women with cervical cancer, HPV 16 was identified in $50.9 \%$ of the cases. Of these, the A1\2 $(31.4 \%)$ sublineage was predominant, followed by the D2 (10.4\%) and D3 $(9.1 \%)$ 
1 sublineages. However, AA variants accounted for $38.7 \%$ of the HPV 16 positive 2 cases.

5 South-Central America, Asia and Africa. 118 cases of squamous cell

A study by Nicolas-Parraga et al. (2017) [27], sought to explore the prevalence of HPV 16 variants in patients with cervical cancer from Europe, carcinoma, 120 of adenocarcinoma, and 53 of adenosquamous carcinoma were observed. Also, the highest prevalence of HPV 16 was observed in patients with squamous cell carcinoma. When examining HPV 16 variants, the A1 - 3 sublineages were predominant in squamous cell carcinomas (76.9 to $97 \%$ for different geographic regions) and there was a large variation for variant $D$ depending on the geographic region in adenocarcinoma (28.6 to $63.3 \%$ for different geographic regions), and adenosquamous carcinoma (12.5 to $61.5 \%$ for different geographic regions).

The data also showed an increase in the prevalence of A1 - 3 in Europe (67.9 to $97 \%$ for all histological types), variant D in South-Central America (61.5 to $63 \%$, for adenocarcinoma and adenosquamous carcinoma), A4 in Asia (from 11.5 to $27.6 \%$ for all types) and variants B and C for Africa (from 28 to $66.7 \%$ and from 12.3 to $37.5 \%$ for ECC and ADC) [27]

These results show a differential association between HPV 16 lineages and the histological features of cervical tumors in different geographic regions. Molecular differences among viral lineages and interactions with tumors may be one of the factors associated with the observed variation in prevalence.

There have also been studies on socioeconomic aspects. A study by Wang et al. (2015) [28] reported that women who received Pap smear test 
1 tended to have higher education levels, corroborating the results of other

2 studies, and that this may be associated with a lack of information and delays in

3 searching for treatment. In a study conducted by Manga et al. (2015) [29] on

4209 women who sought care for cervical cancer screening, the mean age was

539.6 years old, and only $15 \%$ of the women were not literate, $88 \%$ were married

6 and $48 \%$ had a paid activity.

7

8

9 the most prevalent variant in HPV 16 patients, corroborating data from the

\section{Conclusions}

In this study conducted in São Luís-MA, it was shown that variant $\mathrm{A}$ was literature that shows a higher prevalence of variant $A$ in mixed populations, as is the case of the Brazilian population.

Further studies are needed to understand the origin and progression of cancer, as well as the relationship between HPV 16 and its variants with the development of lesion, a cervical cancer precursor. The data presented here may help the development of future epidemiological studies on HPV 16 variants, as well as in the creation of strategies to combat the types that remain circulating, and which were not included in the currently available vaccines against HPV. 


\section{Abbreviations}

2 DNA: deoxyribonucleic acid; HPV: Human Papillomavirus; ICF: Informed

3 Consent Form; INCA: National Institute of Cancer; RNA: ribonucleic acid

\section{Declarations section}

\section{$5 \quad$ Ethics approvals and consent to participate}

6 This project was approved by the Research Ethics Committee of the Federal

7 University of Maranhão (CEP-UFMA), under Consolidated Opinion №

8 1.289.419/2015. All women have signed an Informed Consent Term to participate

9 of this research.

\section{Consent to publish}

11 All women have signed an Informed Consent Term for data publication.

12 Availability of data and materials

13 All data is included in the manuscript file. The data is available with the 14 researches in their own data bank.

\section{Competing interests}

16 The authors declare that there are any conflicts of interest in this work

\section{Funding}

18 Fundação de Amparo à Pesquisa e ao Desenvolvimento Científico e 19 Tecnológico do Estado do Maranhão (FAPEMA). EDITAL UNIVERSAL$20 \quad 00668 / 15$. 
1 FAPEMA has supported the material and equipments acquisition for this

2 research.

3

4 RLS, ZSB, FCBV and MDSBN participated in interpretation of data, drafted and

5 critically revised the manuscript. RLS, MAMM, FVF, ZSB, LMOB, MCLB and

6 MDSBN contributed to study design, interpretation of data, and critically revised

7 the manuscript. MACNS, GRB, APAC, LOC and LAP analyzed and assisted in

8 interpretation of the data and assisted in drafting the manuscript. WEMF, DFS,

9 MCB and ECF contributed to interpretation of data and critically revised the manuscript. All authors read and approved the final manuscript.

\section{Acknowledgments}

We thank to National Institute of Cancer, Genetic Division to HPV variants analyses.

\section{References}

1. Bahls L, Yamakawa R, Zanão K, Alfieri D, Flauzino T, Delongui F, et al. Human Leukocyte Antigen Class I and Class II Polymorphisms and Serum Cytokine Profiles in Cervical Cancer. Int J Mol Sci. 2017 Aug 31;18(9).

2. Barroeta JE, Adhikari-Guragain D, Grotkowski CE. Cervical cancer screening in the era of HPV vaccination: A review of shifting paradigms in cytopathology. Diagn Cytopathol. 2017 Oct;45(10):903-914. 
1 3. Instituto Nacional de Câncer. Estimativa 2018: incidência de câncer no Brasil

2 / Instituto Nacional de Câncer José Alencar Gomes da Silva. Coordenação de

3 Prevenção e Vigilância. - Rio de Janeiro: INCA, 128p. 2017.

4 4. Doorbar J, Egawa N, Griffin H, Kranjec C, Murakami I. Human papillomavirus 5 molecular biology and disease association. Rev Med Virol. 2015 Mar;25 Suppl $6 \quad 1: 2-23$

7 5. Hang D, Yin Y, Han J, Jiang J, Ma H, Xie S, et al. Analysis of human 8 papillomavirus 16 variants and risk for cervical cancer in Chinese population. 9 Virology. 2016 Jan 15;488:156-61

6. Bernard HU, Calleja-Macias IE, Dunn ST. Genome variation of human papillomavirus types: phylogenetic and medical implications. Int J Cancer. 2006 Mar 1;118(5):1071-6.

7. Xi LF, Koutsky LA, Hildesheim A, Galloway DA, Wheeler CM, Winer RL, et al. Risk for high-grade cervical intraepithelial neoplasia associated with variants of human papillomavirus types 16 and 18. Cancer Epidemiol Biomarkers Prev. 2007 Jan;16(1):4-10.

8. Chen W, Molijn A, Enqi W, Zhang X, Jenkins D, Yu X, et al. The variable clinicopathological categories and role of human papillomavirus in cervical adenocarcinoma: A hospital based nation-wide multi-center retrospective study across China. Int J Cancer. 2016 Dec 15;139(12):2687-2697

9. Bernard HU. The clinical importance of the nomenclature, evolution and taxonomy of human papillomaviruses. J Clin Virol. 2005 Mar;32 Suppl 1:S1-6. 
1 10. Tamegão-Lopes BP, Sousa-Júnior EC, Passetti F, Ferreira CG, de Mello

2 WA, Duarte Silvestre RV. Prevalence of human papillomavirus infection and 3 phylogenetic analysis of HPV-16 E6 variants among infected women from 4 Northern Brazil. Infect Agent Cancer. 2014 Aug 5;9:25.

5 11. Chen AA, Gheit T, Franceschi S, Tommasino M, Clifford GM; IARC HPV 6 Variant Study Group. Human Papillomavirus 18 Genetic Variation and Cervical 7 Cancer Risk Worldwide. J Virol. 2015 Oct;89(20):10680-7.

12. Vidal JP, Felix SP, Chaves CB, Patury P, Franco VF, de Morais EA. Genetic diversity of HPV16 and HPV18 in Brazilian patients with invasive cervical cancer. J Med Virol. 2016 Jul;88(7):1279-87

13. Castellsagué X, Schneider A, Kaufmann AM, Bosch FX. HPV vaccination against cervical cancer in women above 25 years of age: key considerations and current perspectives. Gynecol Oncol. 2009 Dec;115(3 Suppl):S15-23

14. Pinho-França JR, Chein MBDC, Thuler LCS. Patterns of cervical cytological abnormalities according to the Human Development Index in the northeast region of Brazil. BMC Womens Health. 2016 Aug 12;16:54.

15. Coutlée F, Gravitt P, Kornegay J, Hankins C, Richardson H, Lapointe N, et al. Use of PGMY primers in L1 consensus PCR improves detection of human papillomavirus DNA in genital samples. J Clin Microbiol. 2002 Mar;40(3):902-7.

16. Vidal FCB, Nascimento MDSB, Ferraro CTL, Brito, LMO. Análise crítica dos métodos moleculares para detecção do papilomavírus humano: revisão da literatura. Femina. 2012. 40(5):264-7. 
1 17. Schiffman M, Doorbar J, Wentzensen N, de Sanjosé S, Fakhry C, Monk BJ.

2 Carcinogenic human papillomavirus infection. Nat Rev Dis Primers. 2016 Dec $3 \quad 1 ; 2: 16086$. 6 S55.

18. Wentzensen N, Schiffman M, Palmer T, Arbyn M. Triage of HPV positive women in cervical cancer screening. J Clin Virol. 2016 Mar;76 Suppl 1:S49-

19. Serrano B, Brotons M, Bosch FX, Bruni L. Epidemiology and burden of HPV-related disease. Best Pract Res Clin Obstet Gynaecol. 2018 Feb;47:14-26

20. Burk RD, Harari A, Chen Z. Human papillomavirus genome variants. Virology. 2013 Oct;445(1-2):232-43.

21. Volpini LPB, Boldrini NAT, de Freitas LB, Miranda AE, Spano LC. The high prevalence of HPV and HPV16 European variants in cervical and anal samples of HIV-seropositive women with normal Pap test results. PLoS One. 2017 Apr 20;12(4):e0176422.

22. Villa LL, Sichero L, Rahal P, Caballero O, Ferenczy A, Rohan T, Franco EL. Molecular variants of human papillomavirus types 16 and 18 preferentially associated with cervical neoplasia. J Gen Virol. 2000 Dec;81(Pt 12):2959-68.

23. Altekruse SF, Lacey JV Jr, Brinton LA, Gravitt PE, Silverberg SG, Barnes WA Jr, et al. Comparison of human papillomavirus genotypes, sexual, and reproductive risk factors of cervical adenocarcinoma and squamous cell 
1 carcinoma: Northeastern United States. Am J Obstet Gynecol. 2003

2 Mar;188(3):657-63.

3 24. Burk RD, Chen Z, Van Doorslaer K. Human papillomaviruses: Genetic basis

4 of carcinogenicity. Public Health Genomics. 2009;12(5-6):281-90.

5 25. Zuna RE, Tuller E, Wentzensen N, Mathews C, Allen RA, Shanesmith R, et 6 al. HPV16 variant lineage, clinical stage, and survival in women with invasive 7 cervical cancer. Infect Agent Cancer. 2011 Oct 28;6:19.

8 26. Alfaro A, Juárez-Torres E, Medina-Martínez I, Mateos-Guerrero N, Bautista9 Huerta M, Román-Bassaure E, et al. Different Association of Human 10 Papillomavirus 16 Variants with Early and Late Presentation of Cervical Cancer. 11 PLoS One. 2016 Dec 30;11(12):e0169315.

27. Nicolás-Párraga S, Alemany L, de Sanjosé S, Bosch FX, Bravo IG; RIS HPV TT and HPV VVAP study groups Differential HPV16 variant distribution in squamous cell carcinoma, adenocarcinoma and adenosquamous cell carcinoma. Int J Cancer. 2017 May 1;140(9):2092-2100

28. Wang B, He M, Chao A, Engelgau MM, Saraiya M, Wang L, Wang L. Cervical Cancer Screening Among Adult Women in China, 2010. Oncologist. 2015 Jun;20(6):627-34.

29. Manga MM, Fowotade A, Abdullahi YM, El-Nafaty AU, Adamu DB, Pindiga $\mathrm{HU}$, et al. Epidemiological patterns of cervical human papillomavirus infection 
1 among women presenting for cervical cancer screening in North-Eastern

2 Nigeria. Infect Agent Cancer. 2015 Oct 2;10:39.

3

4

5

6 Figure Legends

7 Figure 1: Prevalence of HPV types in cervical cancer tissues

8 Figure 2: Phylogenetic tree of HPV 16 with lineages. The tree was constructed

9 using Neighbor-Joining with pairwise deletion. The numbers at each node are 10 bootstrap values (with 1000 replicates). 